Revista Mídia e Cotidiano

Artigo Seção Temática

Volume 11, Número 3, dezembro de 2017

Submetido em: 20/11/2017

Aprovado em: 30/11/2017

\title{
TIPIFICANDO O ATÍPICO: a performance de gênero de Pabllo Vittar no Instagram
}

\section{TYPIFYING THE ATYPICAL: the gender performance of Pabllo Vittar on Instagram}

\author{
Ana Paula COSTA ${ }^{1}$; Lucas BRAGANÇA ${ }^{2}$; Fábio GOVEIA ${ }^{3}$
}

\section{Resumo:}

O presente artigo investiga a narrativa imagética e performática da drag queen Pabllo Vittar no Instagram a partir de um levantamento das publicações feitas pela cantora de 19 de abril a 11 de agosto de 2017, respectivamente as datas de lançamento do videoclipe de K.O - a música que catapultou sua carreira - e quando o mesmo vídeo alcançou 100 mil visualizações no YouTube. Por meio do levantamento do material coletado, estabelecemos uma tipologia das imagens e análise do engajamento dos internautas, para entender como a artista justapõe os binômios de gênero e ajuda a expandir e ressignificar as relações entre corpo, gênero e sexo.

Palavras-chave: drag queen, gênero, performance, redes sociais.

\begin{abstract}
:
This article investigates the imaginative and performative narrative of the drag queen Pabllo Vittar on Instagram from a data survey of the singer's publications made by the singer from April 19 to August 11,2017, respectively the release dates of the music video of K.O. - music that boosted her career - and when the same video reached 100,000 views on YouTube. Through the collected material, we established a typology of images and analysis of internet users' engagement to understand how the artist juxtaposes the gender binomials and helps to expand and re-signify the relationships between body, gender and sex.
\end{abstract}

Keywords: drag queen; gender; performance; social network.

\footnotetext{
${ }^{1}$ Mestranda do programa de Pós-Graduação em Comunicação e Territorialidades da Universidade Federal do Espírito Santo. Pesquisadora do Laboratório de Estudos sobre Imagem e Cibercultura (Labic) da Ufes. E-mail: anapaulamirandacosta@hotmail.com

${ }^{2}$ Mestrando em Comunicação e Territorialidades na Universidade Federal do Espírito Santo. Graduado em Comunicação Social (Publicidade e Propaganda) pela mesma instituição. Bolsista da Capes e integrante do Laboratório de Estudos sobre Imagem e Cibercultura (Labic). E-mail: lucasbragancafonseca@gmail.com

${ }^{3}$ Professor do POSCOM em Comunicação e Territorialidades da Ufes. Doutor em Comunicação pela UFRJ, instituição pela qual também é mestre em Comunicação e Cultura. Possui graduação em Jornalismo pela Ufes. Professor adjunto do Departamento de Comunicação da Ufes. Coordena o Laboratório de Estudos sobre Imagem e Cibercultura (Labic). E-mail: fabiogv@gmail.com
} 
Introdução

A conectividade telemática generalizada, capaz de ampliar o potencial comunicativo dos indivíduos, deu origem ao cenário cotidiano midiatizado, em que as mídias digitais surgem como um verdadeiro tecido conjuntivo da sociedade (SHIRKY, 2011), garantindo conexão permanente e visibilidade. As plataformas móveis com acesso à internet configuram os meios de ser e estar no mundo atual, pautando as maneiras de estabelecer relações com os outros (SIBILIA, 2016).

A forma de produção de subjetividade contemporânea é o ponto de partida de nosso artigo, que pretende analisar a construção da narrativa de si pela perspectiva particular de uma drag queen, no caso, Pabllo Vittar. A cantora utiliza os meios de autocomunicação de massa contemporâneos, sobretudo o Instagram, para divulgar seu trabalho na internet, ao mesmo tempo em que constrói uma narrativa imagética queer ${ }^{4}$, mesclando elementos dos gêneros masculino e feminino.

A necessidade de mimetização do homem em mulher teve seu início em conjunto à história do teatro, portanto, é nesse momento também que a história da performance drag tem seu início. A histórica exclusão das mulheres do espaço público social que as relegava aos afazeres domésticos acarretou ao homem a função da interpretação de personagens femininos tanto no teatro grego, quanto no período medieval e em culturas orientais (BAKER, 1994). Assim, historicamente a performance de gênero "drag" vinha sistematicamente atrelada ao patriarcalismo social, reafirmando, também, como os determinismos do que é masculino e feminino.

De acordo com Amanajás (2014), no que tange a visão da performance drag com algo pejorativo, foi principalmente através da criação da drag pantomímica, uma categoria popular de ator que atuava em comédias travestido de mulheres do cotidiano, geralmente fazendo uso do leque, que esse pensamento se consolidou.

\footnotetext{
${ }^{4}$ Em sua tradução literal do inglês, a palavra queer significa estranho, excêntrico, abjeto, esquisito. Uma palavra até então utilizada para ofender, foi apropriada e utilizada por intelectuais e artistas como uma abordagem política das diferenças.
} 
Esse tipo de performance seguiria em curso até as transformações sofridas pelas guerras na década de 40, onde o papel do homem na interpretação de mulheres no teatro precisou ser revisto dado o novo pensamento da mulher e sua posição na sociedade. (AMANAJÁS, 2014).

Sendo as drags umas das protagonistas da revolta em Stonewall em 1969, momento crucial para o movimento político LGBT, o papel desse grupo social se transformou:

Em meados dos anos 70 [...] ser gay se tornou um ato político e, uma vez que ser artista é, em si, um ato político e social, mesmo que não intencional, a drag queen despontou como um dos maiores símbolos da luta pelos direitos gays. (AMANAJÁS, 2014, p.18)

A liberação sexual que vinha crescendo acabou não durando muito tempo, já que a crise da AIDS fez a comunidade gay ser ainda mais hostilizada ${ }^{5}$. Com o passar do tempo, mesmo em ambientes gays, a cultura drag acabou ficando cada vez mais restrita e marginalizada dado o padrão heterossexista progressivamente enraizado na cultura gay, que enaltece o masculino e discrimina o afeminado.

Nesse contexto, estudar a construção de imagem de uma drag queen torna-se salutar, visto que atualmente essa visão vem se modificando a princípio, pela popularização do programa RuPaul's Drag Race ${ }^{6}$ exibido nos Estados Unidos e, no Brasil, através da ascensão de Pabllo Vittar como uma das maiores artistas pop nacional.

\section{Pabllo Vittar, performance e carreira}

Todo comportamento social é construído tendo como base dicotomias que nos diferenciam e nos disciplinam, obrigando a todos a se colocarem no mundo através de seus corpos e de sua subjetividade de maneira inteligível para o contexto social. Essa

\footnotetext{
${ }^{5}$ O documentário How to survive a plague (2012) de David France é bem ilustrativo da realidade sofrida pela comunidade soropositiva em meio à crise da AIDS.

${ }^{6}$ RuPaul's Drag Race é um reality show de competição que tem como figura central RuPaul, uma notória drag queen nos Estados Unidos. No Brasil há uma grande comunidade de fãs que assistem o programa através do serviço de streaming Netflix e de downloads ilegais.
} 
[...] tentativa de dar inteligibilidade a um corpo é, via de regra, o gesto de engendrá-lo sob alguma forma de reconhecimento a qual tem por base normas sociais, estatais ou médico-jurídicas vigentes. Ler um corpo é tramar-lhe signos: um nome, uma raça, um sexo, uma deficiência, um gênero, uma sexualidade. Ler um corpo é reconhecê-lo por meio da linguagem, é observálo por dispositivos e normas, regimes de poder e biotecnologias. (KLEAIN, 2016, p.10)

Pabllo Vittar vem percorrendo um caminho sem precedentes no sentido de se tornar, não só uma drag queen nacionalmente, mas de ser uma das maiores promessas da música pop brasileira. No entanto, sua performance de gênero não necessariamente pode ser entendida como transgressora.

Como coloca Butler (2015), a performance de gênero das drag queens não é intrinsecamente subversiva, visto que também pode reproduzir a direta relação entre sexo, gênero e desejo, colaborando assim, com a reafirmação do que é relativo ao universo masculino e feminino. Dessa maneira, ter como objeto de estudo uma drag queen é algo complexo, visto que, mesmo que encaremos a performance como subversiva, alguns movimentos sociais, por exemplo, a ala radical do feminismo, costumeiramente entendem a performance drag masculina ${ }^{7}$ como outra forma de estereotipar e oprimir a mulheres a partir da visão que seriam homens utilizando signos femininos.

Não há como obter uma conclusão simplista sobre o assunto, especialmente porque não necessariamente esses homens correspondem aos ideais de masculinidade e sua performance, mesmo utilizando signos tradicionalmente entendidos como femininos, podem ser interpretados como 'seres híbridos' que no momento da performance não se adequam a que se espera dos ideais masculinos e femininos.

Phabullo Rodrigues da Silva (nome de batismo de Pabllo Vittar), maranhense, iniciou sua carreira em 2015 com o single "Open Bar" (uma paródia de "Lean On" de Major Lazer com DJ Snake e Mø), mesclando ritmos brasileiros ao pop internacional. No fim do mesmo ano, Pabllo Vittar divulgou um $\mathrm{EP}^{8}$ com mais versões de faixas

\footnotetext{
${ }^{7}$ Falamos aqui de performance drag masculina visto que contemporaneamente há diversas outras variações de drag, como as faux queens (mulheres que se montam como drag queens), as drag kings (mulheres que se montam utilizando elementos masculinos).

8 Disponível em $<$ http://bit.ly/2vsRnll $>$. Acesso em 22/08/2017.
} 
estrangeiras. A partir daí, entrou em franca ascensão de popularidade, chegando inclusive a ser elenco fixo da banda do programa “Amor \& Sexo" da Rede Globo 9 .

A virada na carreira de Pabllo Vittar aconteceu em janeiro de 2017, ao lançar o disco autoral "Vai Passar Mal", que contou com produção do DJ americano Diplo. O álbum foi pioneiro em ter como protagonista uma drag queen cantando composições próprias. Nesse álbum se destaca a faixa "K.O”, cujo videoclipe, lançado em 19 de abril de 2017 pela artista, alcançou 100 milhões de visualizações no YouTube em menos de dois meses ${ }^{10}$.

A artista também foi convidada para participar do EP do grupo eletrônico Major Lazer, que conta com Diplo entre seus membros. Lançado em $1^{\circ}$ de junho de 2017, a música trouxe Pabllo Vittar dividindo os vocais com Anitta na faixa "Sua Cara". O videoclipe da música, gravado no Marrocos e divulgado no dia 30 de julho, alcançou 100 milhões de visualizações no YouTube em menos de um mês de divulgação ${ }^{11}$.

Tamanha repercussão em seus clipes deu projeção a Pabllo Vittar nos sites de redes sociais. Postando vídeos e fotos no Instagram (@pabllovittar), a artista se tornou em junho de 2017 a drag queen mais influente da internet ao atingir 1,4 milhão de seguidores na rede social em questão, desbancando drag queens influentes como $\mathrm{RuPaul}^{12}$, notória drag queen americana famosa desde os anos 1990, que comanda o reality show “RuPaul's Drag Race”, produzido desde 2009. Atualmente com 3,7 milhões de seguidores ${ }^{13}$, poucos meses após se tornar a drag queen mais influente do Instagram, Pabllo se firma como a drag queen que mais impacta outras pessoas através de suas redes sociais.

A artista, que desde 2015 divulgava seu material de forma independente via plataformas digitais, assinou contrato a gravadora multinacional Sony Music para

\footnotetext{
${ }^{9}$ Disponível em $<$ https://glo.bo/2vsPWU9 $>$. Acesso em 22/08/2017.

${ }^{10}$ Disponível em $<$ https://www.instagram.com/pabllovittar $>$. Acesso em 02/09/2017.

${ }^{11}$ Disponível em $<$ http://bit.ly/2wwjb9W $>$. Acesso em 02/09/2017.

12 Disponível em $<$ http://bit.ly/2w19kL9 $>$. Acesso em 22/08/2017.

${ }^{13}$ Disponível em $<$ http://bit.ly/2yGpgB3 $>$. Acesso em 02/09/2017.
} 
produção de dois álbuns ${ }^{14}$. Também recebeu convites para gravar com artistas como Lucas Lucco, Preta Gil e Alice Caymmi ${ }^{15}$, além de ter participado do show da cantora Fergie no principal palco do Rock in Rio.

Se, conforme Shirky (2011), as mídias sociais não são apenas uma alternativa para a vida real, mas são uma parte importante dela, compreender como se dá uma relação comunicacional que esbarra em questões de subjetividade em um indivíduo intrincado em questionamentos sociais das mais variadas abordagens sexuais e identitárias, se torna algo significativo.

Sendo assim, no presente artigo investigamos a narrativa imagética de Pabllo Vittar no Instagram, no período de 19 de abril a 11 de agosto de 2017, ocasião em que foi lançado o videoclipe de "K.O.", faixa que conquistou 100 milhões de visualizações ao fim do recorte temporal considerado para a coleta de dados. Em nosso monitoramento, propomos uma análise de conteúdo das quatro postagens que obtiveram mais curtidas e das quatro imagens com mais comentários dentro do período proposto para a investigação, além de estabelecermos uma tipologia do conjunto de imagens postadas pela artista.

\section{Conectividade e sociabilidade generalizada}

$\mathrm{Na}$ contemporaneidade nos encontramos tão envoltos aos aparados tecnológicos que já não mais racionalizamos seus usos. As telas e seus conteúdos são hoje uma parte de nós nesse universo desterritorializado fisicamente, mas densamente habitado virtualmente. Nesse ambiente, como nos fala Shirky (2011, p.37) os sites de redes sociais "tornam-se cada vez mais os instrumentos coordenadores de eventos no mundo físico" e, para além disso, tornam-se plataformas de sociabilidade com os outros.

Dessa forma, as redes sociais representam não apenas um espaço de trocas e interações em um processo participativo de discussão sobre os mais diversos assuntos e temas que toquem a sociedade, mas também "espaços vivos que conectam todas as

\footnotetext{
${ }^{14}$ Disponível em $<$ http://bit.ly/2ftXinU $>$. Acesso em 02/09/2017.

${ }^{15}$ Disponível em $<$ https://glo.bo/2x4gZtw $>$. Acesso em 02/09/2017.
} 
dimensões da vida das pessoas" (CASTELLS, 2013, p.173) e que criam um ambiente onde os indivíduos se fazem presente e se colocam no mundo através de uma comunicação particular experienciada coletivamente. Em outras palavras, como aponta Raquel Recuero (2014, p.24), “essas ferramentas proporcionam que atores pudessem construir-se, interagir e comunicar com outros atores ${ }^{16}$, deixando rastros que permitem o reconhecimento dos padrões de suas conexões e visualização de suas redes sociais".

$\mathrm{Na}$ perspectiva que compreende o advento e popularização tanto dos computadores e da internet (e, mais recentemente dos smartphones) como fundamentais para explicação das mudanças que a sociedade vem experienciando, a mais relevante entre elas "é a possibilidade de expressão e sociabilização através das ferramentas de comunicação mediada pelo computador" (RECUERO, 2014, p.24). O uso do Instagram, especificamente, pode, de certa forma, estender a especificidade dos registros em fotos e vídeos em uma composição narrativa linear e hipertextual que visa uma comunicação de si para o mundo.

Como estabelece Clay Shirky (2012), neste novo contexto midiatizado e informatizado, todo mundo passa a ser um veículo de comunicação. Para o autor "nossas ferramentas sociais removem obstáculos mais antigos à expressão pública, eliminando assim os gargalos que caracterizavam os meios de comunicação de massa" (SHIRKY, 2012, p. 51) tornando possível comunicar assuntos que, anteriormente, estariam ligados à marginalidade, como a questão drag.

\section{Narrativas midiáticas e experimentação na rede}

A criação de uma narrativa imagética apresenta-se mais complexa na sociedade atual, que tem suas tramas permeadas pela interseção com a mídia digital. A experimentação na rede transfigura, e pode, de certa maneira, estender a especificidade

\footnotetext{
${ }^{16}$ Os atores no ciberespaço, na visão da autora e aqui compartilhada, compreendem os "indivíduos que agem através de representações performáticas de si mesmos” (RECUERO, 2014, p. 28).
} 


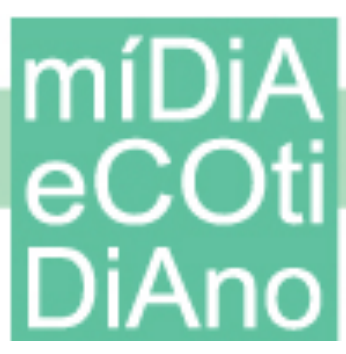

dos registros em fotos e vídeos em sites de redes sociais, como por exemplo o Instagram, que passam a compor e abrigar simultaneamente narrativas lineares e hipertextuais.

A cultura técnica contemporânea, denominada cibercultura, forma-se a partir da convergência entre os elementos sociais e os tecnológicos, sendo "através da inclusão da socialidade na prática diária da tecnologia que ela adquire seus contornos mais nítidos" (LEMOS, 2013, p. 90). Dessa forma, a dinâmica da sociedade está em sintonia com a cibercultura.

Imergindo nessa cultura da convergência (JENKINS, 2009), surgem novos atores que estabelecem uma narrativa, que se desenvolve aliando diferentes plataformas e linguagens. Este novo formato dá origem a uma história contada em múltiplas mídias. Para Scolari (2015, p.8): “esta dispersão textual é uma das fontes mais importantes da complexidade na cultura popular contemporânea".

Com a popularização de aparatos tecnológicos com acesso à internet e a vários recursos de produção de textos, imagens e vídeos, o público deixa o papel de consumidor passivo de informações, e passa a elaborar conteúdo. Os smartphones, ou telefones inteligentes, plataformas móveis conectadas à internet que trazem recursos de texto, imagem e vídeo, permitem a junção de duas premissas: visibilidade e conexão. Esses aparelhos "conseguiram dar vazão às peculiares demandas e ambições que articulam as subjetividades contemporâneas, bem como ao tipo de sociabilidade por elas alicerçada" (SIBILIA, 2016, p. 21).

A rede mundial de computadores configura-se atualmente como um grande laboratório, um espaço oportuno para "experimentar e desenvolver novas subjetividades e outras formas de se relacionar com os demais" (SIBILIA, 2016, p. 52-53). São nos diversos canais da internet que surgem novas formas de ser e estar no mundo, "que por vezes parecem saudavelmente excêntricos e megalomaníacos, mas outras vezes afundamse na pequenez mais rasa que se pode imaginar" (SIBILIA, 2016, p. 53). 


\section{míDiA

\section{Eu-drag no ciberespaço}

Se vivemos em uma produção coletiva de significados que vem modificando diversas instituições e estruturas sociais, os sites de rede social fornecem meios para que todo indivíduo, através da transmissão de si e de seus valores, colabore com uma coletividade na busca por mudanças (e, muitas vezes pelo mantenimento) de questões sociais. Muitas vezes acabamos por criar e viver em uma bolha ideológica, nos comunicando apenas com nossos pares, ou seja, com pessoas que compartilham um mesmo ideário. No entanto, mesmo essa comunicação pode ser poderosa se vermos pela perspectiva de que ela retroalimenta os discursos e os potencializa. Assim, a partir do nascimento desses novos modos de ser e estar no mundo, os usuários, cada vez heterogêneos, através de suas performances na rede, vão criando discursos que vão se aglutinando a outros.

No caso das questões de gênero e sexualidade percebe-se uma movimentação social que vem tentando redesenhar algumas preconcepções ou mesmo demonstrar o caráter artificial estabelecido acerca dessas questões. $\mathrm{O}$ ressurgimento dessas lutas tem bases diversas, mas encontra no ambiente digital uma das formas mais poderosas de proliferação.

Se a sociedade já vivia em um ambiente espetacularizado, atualmente, através da internet e das redes de sociabilidade digitais, estamos, de acordo com Sibilia (2016) em um novo cenário espetacular, o do show do eu. Nesse universo, nossa subjetividade é percebida como nosso modo de ser e estar no mundo, sendo que "seus contornos são elásticos e mudam ao sabor das diversas tradições culturais” (SIBILIA, 2016, p. 26).

Não há como precisar a parcela de importância que as redes sociais tiveram no ressurgimento das disputas de caráter sexuais e identitárias na contemporaneidade, mas percebendo o cenário atual aos olhos de Sibilia (2016) é fácil compreender que nos encontramos em meio a um desses "momentos elásticos" a qual a autora se refere, em que questões dadas como indiscutíveis até pouco tempo vêm sendo questionadas e perdem espaço. 
É assim, nesse ambiente, que a drag queen Pabllo Vittar se posiciona. Em suas redes a artista se coloca não apenas como um produto mercadológico e midiático, mas como um ser social que a partir de sua performance dentro do ambiente digital tenta deslegitimar os binômios homem-mulher, masculino-feminino, etc. Se atualmente encontramos espaço para que esse fenômeno se expanda, pode-se supor que mudanças sociais estão ocorrendo, não apenas em uma perspectiva histórica, mas também nas maneiras de se relacionar com o outro, e que, dentro desse novo contexto, "o campo da experiência subjetiva também se altera, num jogo extremamente intricado, múltiplo e aberto" (SIBILIA, 2016, p. 27).

Por meio da internet e da convergência midiática, é verificado atualmente "um verdadeiro festival de vidas privadas que se oferecem despudoradamente aos olhares do mundo inteiro" (SIBILIA, 2016, p. 52). Como consequência, cria-se uma cultura das aparências, do espetáculo, da visibilidade que acabam se tornando características do cenário midiatizado atual. Para Sibilia (2016, p.151) as "tendências exibicionistas e performáticas alimentam a procura de um efeito: o reconhecimento nos olhos alheios e, sobretudo, o cobiçado troféu de ser visto", fazendo com que, nesse ambiente só existe quem aparece.

Os indivíduos que conseguem alcançar notoriedade em meio a uma disputa narrativo-imagética se tornam célebres. Para França (2014), celebridades se referem a pessoas que, por causa de uma qualidade ou feito se tornam celebradas ou reconhecidas. Para França (2014, p. 24), essas personalidades ostentariam "aquilo que uma determinada sociedade, num determinado momento, valoriza".

Essa ideia, contudo, não pode ser entendida como totalidade quando a observamos empiricamente. No caso de Pabllo, por exemplo, mesmo sendo uma drag queen cada vez mais notória, a sociedade não é amplamente a favor de suas performances de gênero tão 
pouco dos questionamentos e incertezas que isso traz, pelo contrário, há, constantemente, ataques à artista e respostas violentas sobre suas aparições midiáticas ${ }^{17}$.

\section{Performances e tipologia no Instagram}

Como forma de compreender o desenvolvimento da narrativa de si, ao moldes do pensamento de Sibilia (2016), em uma figura pública, não apenas dependente das questões de imagem, mas no caso de uma drag queen, fundada em bases representativas que a adequa visualmente em gêneros distintos, preferimos realizar uma análise de conteúdo da plataforma Instagram e, dessa maneira, entender não apenas como a artista se coloca dentro da rede social, mas como os usuários interagem com o que é proposto pela artista. A análise baseada em categorização dessas imagens, fornece, aos moldes de Recuero (2014, p.36): "padrões de interação que definem uma relação social que envolve dois ou mais agentes ou indivíduos comunicantes".

A escolha do Instagram como plataforma de análise não é arbitrária. Se pretendemos compreender a figura de Pabllo por meio de sua visualidade estética e através da maneira como ela se coloca na rede e é compreendida por outros, a rede social se apresenta como a mais eficiente, visto que é baseada nas publicações de imagens pelo próprio usuário. Além disso, a plataforma permite ver através das curtidas, quais imagens são as mais tocadas pelo público, bem como quais geram maior diálogo e debate entre os usuários na rede, já que também é possível comentar e contabilizar esses comentários nas imagens publicadas.

Para fazer essa análise nos deparamos com uma problemática: se entendemos as drag queens como uma performance de gênero que não se enquadra nos binômios masculino-feminino, porque então categorizá-las? Fato é que, correndo o risco de enquadrar algo fluido em categorias rígidas, pretendemos que esse processo facilite a

\footnotetext{
${ }^{17}$ Um dos mais recentes ataques contra Pabllo foi a invasão de sua conta no YouTube em que o hacker deletou seu clipe K.O. e colocou uma foto do deputado Jair Bolsonaro (conhecido por seu posicionamento

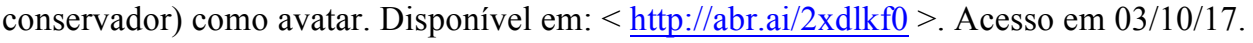


percepção tanto do que a artista quer transmitir através de suas publicações quanto de que forma os indivíduos percebem essa comunicação.

Foram determinadas quatro categorias para determinar alguns padrões, ou seja, evidenciar uma tipologia. Duas delas, $\operatorname{montada}^{18}$ e desmontada, são correlatas e enquadram a performance estética e de projeção de si de Pabllo Vittar no Instagram em momentos que ela se coloca enquanto drag e quando não. Evitamos classificações como "masculino e feminino" visando fugir das padronizações sociais e delimitadoras aqui questionadas. Como forma de criar um lugar-outro que não enquadrado nas concepções duais entre masculino e feminino, criamos também a categoria "dúbia" em que Pabllo mescla de forma expressiva sua masculinidade e feminilidade em uma só imagem, ou seja, são publicações em que a artista se encontra mais nitidamente em um lugar entregênero (ou intergênero). Para além disso, temos também a categoria "outros" que incluem imagens que não tem Pabllo como peça central da imagem. Não obstante, compreendemos que, de certa maneira, as interpretações imagéticas se valem da experiência do receptor, sendo essa uma tentativa de compreender um objeto complexo de maneira não particular.

Em primeira instância, fizemos uma análise de conteúdo da artista considerando, aqui, o lançamento do clipe de "K.O." como o momento de catarse expositiva em sua conquista de um público nacional amplo. Assim, observamos como foi realizada a comunicação na plataforma até que o vídeo alcançasse sua primeira centena de milhão de visualizações no YouTube.

O período analisado foi do dia 19 de abril de 2017 ao dia 11 de agosto de 2017 os quais representam, respectivamente, a data de lançamento do videoclipe "K.O." e o dia em que o vídeo alcançou 100 milhões de visualizações no YouTube. A coleta foi feita de forma manual, levantando uma amostra de 181 postagens a serem analisadas a partir do engajamento dos internautas.

\footnotetext{
${ }^{18}$ Se montar é uma gíria pertencente ao léxico gay, o pajubá, que significa se arrumar para algo. Dentro do universo drag isso quer dizer se produzir como drag queen.
} 


\begin{tabular}{|c|c|}
\hline \multicolumn{2}{|c|}{ Categorizando Conteúdos } \\
\hline Montada: 139 & Desmontada: 25 \\
\hline Dúbia: 4 & Outras: 13 \\
\hline
\end{tabular}

Tabela 1: categorização das 181 imagens pertencentes ao recorte do estudo

Primeiramente saltam aos olhos a diferença de imagens em que a artista se encontra vestida em drag em detrimento ao número de publicações em que não está. Partindo da compreensão de que a base de reconhecimento e de popularidade de Pabllo Vittar como artista é ser uma drag queen, o fato é compreensível. Como o próprio nome de usuário da rede diz, o Instagram pertence a Pabllo Vittar, um alterego de um artista, muito mais do que um perfil pessoal e íntimo.

As imagens dúbias, apesar de numericamente pequenas são expressivas no que tange à percepção de gênero da artista. Se, conforme coloca Butler (2016), a performance de gênero das drag queens podem ser utilizadas para reafirmar ou questionar as predefinições de masculinidade e feminilidade, Pabllo, nessas imagens, brinca com essas concepções, mostrando o quão artificial esses universos são. Para além disso, a categoria “dúbia” é, como o próprio nome diz, duvidosa, no sentido de que é extremamente mutável de acordo com a sensibilidade de quem percebe essas imagens. Phabullo, mesmo enquanto não performando Pabllo Vittar, não corresponde aos critérios e padrões de masculinidade socialmente aceitos. Assim, sua apreensão como um indivíduo masculino ou feminino depende das preconcepções que o olhar do usuário possui.

Quando percebemos que dentro de todo o universo analisado de 181 imagens, apenas 13 delas não são imagens que tenham diretamente a imagem de Pabllo, vemos que sua página funciona não apenas como uma plataforma de divulgação de seu trabalho, mas também de performance de si. Considerando que, na sociedade contemporânea, o homem age a todo momento como um ator diante de seu público, como afirma Erving Goffman, citado por Oikawa (2013), observamos que os indivíduos dentro dos sites de redes sociais estabelecem performances esteticamente pensadas para suas audiências, pois tentam “controlar as impressões que os outros possam ter dele, por meio de diferentes modos de 
agir e de se comportar, que variam de acordo com seus propósitos” (OIKAWA, 2013, p. 94).

A partir da visualização de que as fotos da artista, montadas e desmontadas, são as mais publicadas, decidimos nos focar também em como são produzidas e realizadas essas fotos com o fim de identificar se a imagem gerada pela artista está mais atrelada a uma produção mercadológica ou pessoal. Dividimos, então, a categoria 'montada' em 'montada selfie' e 'montada outros', bem como a categoria 'desmontada' em 'desmontada selfie' e 'desmontada outros'.

\section{Montada x Desmontada}

\begin{tabular}{|c|c|}
\hline Montada Selfie: 47 & Montada Outros: 92 \\
\hline Desmontada Selfie: 18 & Desmontada Outros: 7 \\
\hline
\end{tabular}

Tabela 2: reenquadramento das 164 imagens das categorias "montadas e desmontadas"

Como já falado, a tipificação de "montada" e "desmontada" em detrimento a "masculino" e "feminino" foi pensada dessa forma pelo fato de ser intangível a compreensão de Pabllo dentro desses binômios, visto que em qualquer desses polos é possível perceber elementos do "universo oposto". Em, por exemplo, postagens de imagens cotidianas através de selfies tiradas no espelho, Pabllo muitas vezes faz uso de roupas indefiníveis pelo gênero, bem como de elementos socialmente compreendidos como masculinos (corte de cabelo curto) e femininos (unhas pintadas) simultaneamente. Pabllo então, não apenas não corresponde às expectativas sociais de gênero, como se faz presente na rede e se comunica como pessoa e artista de maneira não normativa, ou, na nossa visão, abrangente ou ampliada das categorias de gênero. Seria incongruente, dessa maneira, a percepção das imagens em momentos que ele se encontra em drag (montada) como feminino e momentos em que não se encontra em drag (desmontada) como masculino.

Nessa tabela é possível perceber como difere as publicações em drag e fora dela. Enquanto Pabllo, vestida de drag, tem o dobro de imagens fotografadas por outras 
pessoas, quando está sem se montar, as selfies são sua principal forma de se colocar na rede. Isso ocorre porque quando montada a drag está geralmente indo a eventos, fazendo shows, entrevistas, etc., e, por isso, está sempre envolta a uma equipe que pode tirar suas fotografias com maior qualidade. Já quando está sem se montar as imagens mostram, em geral, Pabllo em ambientes mais íntimos. Estabelece-se assim, uma relação imbricada entre a prática do selfie e a intimidade, enquanto as fotos tiradas por terceiros são, em maioria, quando a drag se encontra montada, ou seja, estão mais atreladas a um viés midiático e mercadológico.

As fotos tiradas por outras pessoas são maioria (99), mas alto número de selfies (65) demonstram que a imagem de Pabllo na rede social possui contornos pessoais, não estando em sua totalidade intrincada à produção de uma imagem coesa e perfeccionista. Isso acaba aproximando seu público que percebe a artista como uma "pessoa comum". Essa questão, quando levada ao âmbito das comunidades LGBT são importantes dado ao fato desses indivíduos sempre serem subrepresentados midiaticamente. As selfies, em sua maioria, tiradas em espelho em residências ou hotéis demonstram o caráter privado e íntimo com que a drag pretende se relacionar com seu público.

\section{Engajamento nas redes}

A narrativa imagética de Pabllo Vittar, composta de vídeos e fotos em várias abordagens de estilo, tem conquistado em um fluxo cada vez mais rápido. No Instagram, como falado, a cantora se tornou a drag queen mais influente do mundo em 28 de junho de 2017, quando alcançou 1,4 milhão de seguidores ${ }^{19}$, mas apenas no intervalo de tempo entre essa data e 2 de setembro de 2017, a artista obteve mais de 2 milhões de novos seguidores, chegando ao número de 3,7 milhões $^{20}$.

Com vista em captar o que da imagem exposta por Pabllo dentro de sua rede social as pessoas mais se identificam, elencamos as quatro publicações mais curtidas. A coleta

\footnotetext{
${ }^{19}$ Disponível em $<$ http://bit.ly/2w19kL9 $>$. Acesso em 02/09/2017.

${ }^{20}$ Disponível em $<$ https://www.instagram.com/pabllovittar $>$. Acesso em 02/09/2017.
} 


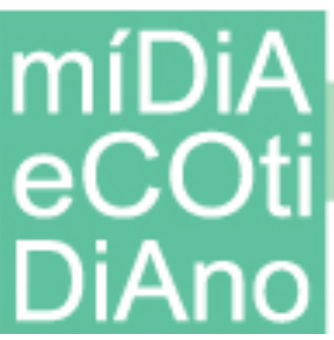

PPGMC

das informações foi realizada no dia 30 de agosto de 2017 e cada uma das quatro postagens obtiveram mais de 500 mil likes cada.
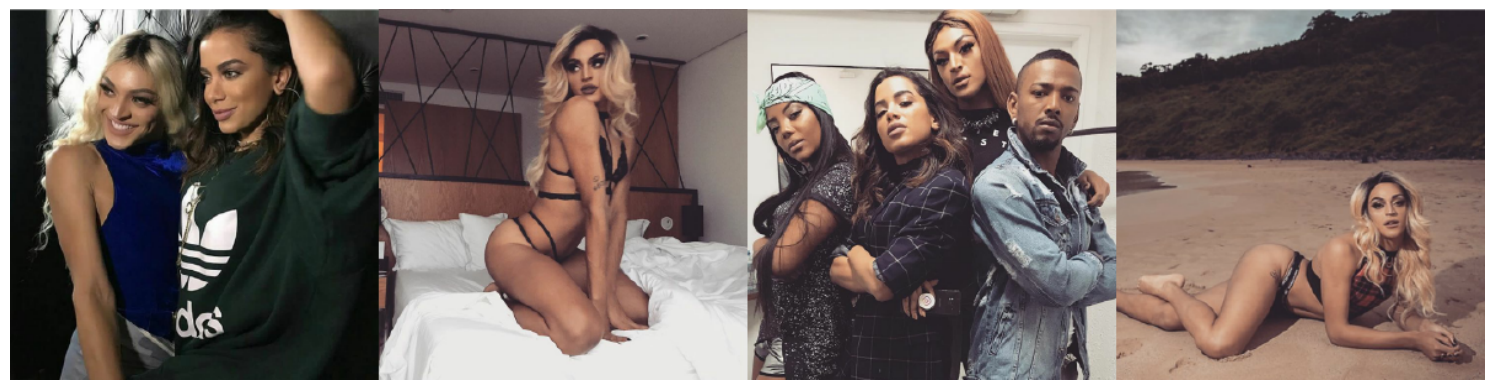

Imagem 1: as quatro postagens com maior número de curtidas em ordem crescente

A publicação com a maior quantidade de curtidas (674.233) traz Pabllo Vittar ao lado da cantora Anitta no dia do lançamento do clipe da música "Sua Cara", uma parceria das duas artistas com o grupo eletrônico internacional Major Lazer. As duas artistas estavam em uma festa no Rio de Janeiro, para promoção do novo trabalho. Na ocasião, havia muita expectativa pelo lançamento do videoclipe das duas cantoras, já que seria o pontapé inicial para o lançamento internacional de ambas. Na legenda Pabllo brinca com um meme ${ }^{21}$ e escreve: "se juntas já causam”. Essa forma de comunicação, típica dos ambientes digitais é ainda mais presenta na comunicação interpessoal LGBT nas redes sociais. O uso desse tipo de linguagem permite a Pabllo gerar mais empatia e proximidade com seus seguidores através do humor.

A segunda postagem mais curtida é uma foto de Pabllo Vittar vestindo um figurino extremamente sensual. A foto conquistou 631.006 likes, e tem como legenda “corpo_sensual.mp3" que remete não apenas à fotografia em si, mas a uma de suas músicas de trabalho "Corpo Sensual". A aceitação por parte do público sobre essa foto tornando-a uma das mais curtidas é a prova de que, ao menos para parte da sociedade, as dimensões sexuais entre os universos masculinos e femininos se encontram desestabilizados, já que Pabllo se apresenta em um look compreendido socialmente como

\footnotetext{
${ }^{21}$ Disponível em $<$ http://bzfd.it/2g8WFh2 $>$. Acesso em 04/10/2017.
} 
feminino, sendo performado por um homem em uma exibição clara de sensualidade e erotismo.

A terceira publicação mais curtida traz Pabllo Vittar ao lado de Anitta, Nego do Borel e Ludmilla, nos bastidores do canal Multishow. A imagem obteve 563.395 curtidas, com a legenda "squad goals". "Squad" é uma palavra inglesa que significa "esquadrão". A foto e sua legenda se tornam uma representação poderosa, pois alinham em uma única imagem três dimensões de lutas sociais que vêm ganhando espaço midiaticamente: a causa LGBT, a causa feminista e a causa racial. A expressão e a linguagem corporal dos artistas também são potentes, já que os artistas se encontram com uma postura que nos remete tanto a união entre eles (e do que representam) quanto de desafio para o espectador. Com o misto de gangue e de irmandade, a imagem demonstra que as lutas minoritárias podem não apenas dialogar, mas se fortalecer.

Pabllo Vittar surge sozinha na quarta postagem mais curtida, de biquíni, deitada na praia, de peruca loira e novamente sensualizando. A foto tem como legenda "high by the beach", uma referência a uma música da cantora Lana Del Rey e obteve 514.355 likes. O registro foi feito em Fernando de Noronha, para um editorial usado em uma reportagem sobre a artista. Aqui, novamente, a sensualidade feminina performada por Pabllo é, não apenas exibida, mas notoriamente celebrada pelos seguidores dado ao número de curtidas.

O que se torna mais evidente quando vemos as fotos mais curtidas da cantora é que sua performance de gênero é prestigiada. Em todas as cinco imagens, Pabllo se encontra produzido sua inteligibilidade corporal e estética a partir de signos e elementos que socialmente compreendemos como femininos. Assim, mesmo em um ambiente social hostil a performances de gênero não normativas, a figura de Pabllo é celebrada justamente por sua incongruência a uma sociedade que tenta encaixar os indivíduos em dicotomias, não compreendendo as pessoas como seres plurais e distintos.

Como forma de expandir ainda mais a pesquisa, analisamos também as quatro postagens mais comentadas dentro do período estipulado. Cada uma delas alcançou mais de 10 mil comentários. São elas: 


\section{míDiA \\ eCOti DiAno}

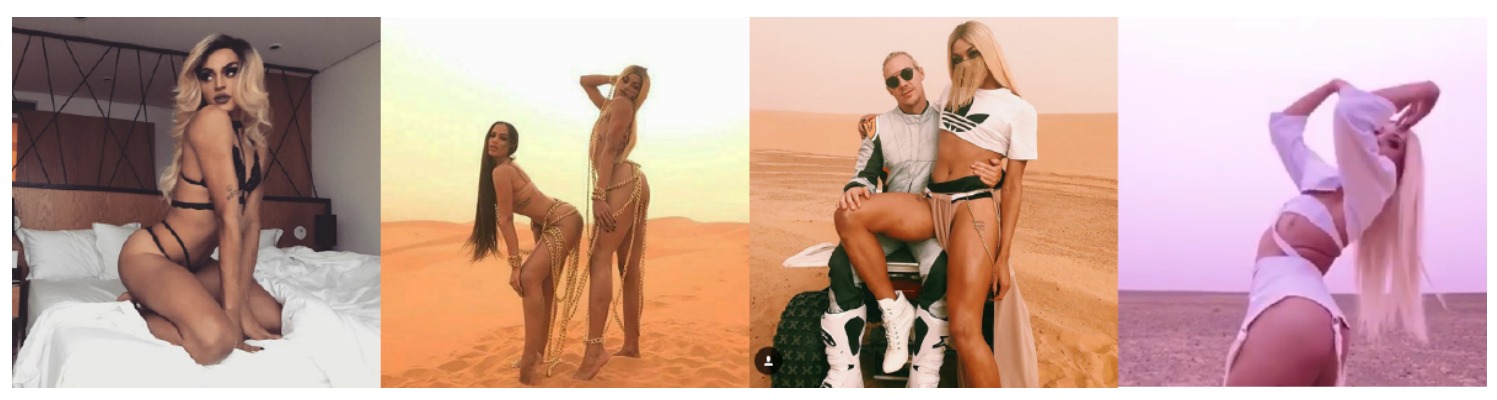

Imagem 2: as quatro postagens mais comentadas em ordem crescente

A publicação que obteve o maior número de comentários traz Pabllo Vittar de lingerie, em cima de uma cama de casal, em uma pose muito sensual. Com 17.038 comentários, o registro, como já falado, também conquistou um amplo número de curtidas. Nos comentários, grande parte dos internautas (homens e mulheres) elogiam a boa forma da cantora. Percebe-se que os comentários sempre se dirigem à Pabllo no feminino. Isso demonstra que a inteligibilidade dos corpos como masculinos ou femininos é dependente dos signos e dos elementos que compõem os corpos e não apenas do sexo natural dos indivíduos. Apesar de ter uma aceitação considerável, visto que a imagem tem muitas curtidas e comentários positivos, é preciso destacar que também há críticas entre os usuários do Instagram sobre o fato de Pabllo Vittar ser um homem performando como mulher. Notamos, porém, que os próprios seguidores da cantora defendem a artista quando há ataques ou críticas, sempre deixando claro que aquele espaço não é viável para homofobia, mas que se concretiza como lugar onde não há limites de gênero para expressão artística e performática.

A segunda postagem mais comentada (14.206 comentários) foi a foto de Pabllo Vittar ao lado de Anitta, vestidas de odaliscas durante as gravações do videoclipe da faixa "Sua Cara". Foi o primeiro clique oficial divulgado pela artista durante as gravações do videoclipe. Na foto, a figura feminina de Pabllo ao lado de Anitta desafia as concepções de masculinidade e feminilidade, apontando, novamente, a artificialidade que se constrói o corpo masculino e feminino. O mais salta nos comentários são os elogios as formas físicas das duas artistas e as comparações entre as duas cantoras, uma prática social habitual que tenta criar certa rivalidade entre artistas. 
A terceira postagem com mais comentários também traz uma foto de Pabllo Vittar durante as gravações de "Sua Cara". No clique, a cantora está no colo do DJ e produtor Diplo, do grupo Major Lazer. Obteve 12.506 comentários. A imagem foi postada antes do lançamento do videoclipe, para aumentar a expectativa dos fãs antes da divulgação do trabalho. Pode-se perceber a imagem como representativa, pois mostra com extrema naturalidade uma relação social que, muitas vezes, é de muita tensão a de homens heterossexuais (conservadores) e homossexuais. Pabllo brinca e desafia ainda mais os usuários colocando a legenda "daddy's girl”, ou "garotinha do papai”. Nos comentários há muitas declarações de amor para Pabllo, e também muitas brigas, com internautas discutindo sobre a aparência, talento ou performance da cantora. Essa relação crítica sobre a artista e as controvérsias que se criam a partir disso acabam por impulsionar a construção imagética da artista dentro do Instagram.

O primeiro e único vídeo que se enquadrou nos critérios de seleção foi a quarta publicação mais comentada com 11.661 comentários. O vídeo obteve 1.754.588 visualizações, sendo divulgado após o lançamento do clipe "Sua Cara", como forma de agradecimento da cantora por conta da ampla repercussão do trabalho. Nas imagens, Pabllo Vittar canta e dança ao lado de Anitta e Diplo nas areias do deserto. Nos comentários, muitos exaltam a beleza estética da gravação e das artistas. Uma novidade são os comentários em outros idiomas, como inglês e espanhol, evidenciando a projeção internacional da cantora com o lançamento desse videoclipe. No registro imagético, mais uma vez, a cantora mescla com o imaginário do público, ao usar um figurino extremamente feminino e sensual.

\section{Conclusões}

Apesar de surgir nas vitrines midiáticas "montada" e "desmontada", constatamos em nossa análise que Pabllo Vittar consegue um maior engajamento entre o público do Instagram quando surge montada. Nas quatro postagens mais curtidas e nas quatro postagens com mais comentários, a artista estava bem maquiada e se apresentando de maneira extremamente sensual utilizando as formas do seu corpo masculino de maneira a aludir um corpo naturalmente feminino. 
Como a própria drag queen colocou em entrevista: ela não se importa de ser chamada por artigos femininos ou masculinos ${ }^{22}$. Isso é uma forma de demonstrar a dinâmica desestabilizadora que Pabllo propõe. A própria escolha de seu nome artístico é reveladora sobre o caráter denunciativo do artista acerca das concepções arcaicas e cristalizadas de gênero. A maioria das drag queens escolhe um 'nome feminino' para seus alteregos, já Pabllo preferiu a utilização de um nome "masculino" para contrapor sua aparência e sua dinâmica mais próximas ao universo feminino.

Sua performance estética, de gênero e comportamental acaba por denunciar a rigidez das concepções culturais atreladas aos universos macho-fêmea da natureza. Ou seja, sua forma de se colocar no mundo justapõe os binômios de gênero e ajuda a expandir e ressignificar as relações entre corpo, gênero e sexo

Tentamos aqui, ao máximo, fugir das caracterizações comportamentais reducionistas percebendo a performance de gênero de Pabllo nas categorias "montada" e "desmontada", mas, mesmo elas se mostram, de certa forma, ineficientes em abranger a complexidade da artista. Ao final do estudo conseguimos compreender que a própria caracterização e enquadramento em categorias é incapaz de ler esse objeto porque sua intenção é justamente a de não se enquadrar. Sua pretensão é mostrar o quanto esse enquadramento é artificial.

No entanto, algumas questões vão emergindo quando adentramos no objeto pela abordagem do olhar dos usuários sobre a artista. Há uma exaltação não apenas a figura feminina de Pabllo, mas à sua sexualidade que grita: sou homem gay, mas posso ser uma mulher atraente e desejável se quiser. Essa provocação não apenas atinge um comportamento social sedimentado, mas também fala diretamente com uma população LGBT que, em maior ou menor grau, já sofreu com imposições sociais que delimitam os universos os quais essas pessoas poderiam se aventurar subjetivamente e corporalmente.

\footnotetext{
${ }^{22}$ Dessa forma, também não nos detivemos a uma rigidez geralmente necessária quando estudos abordam

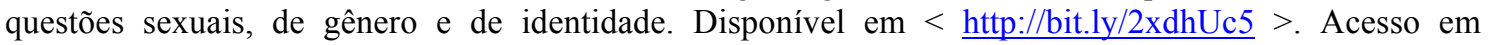
02/09/2017.
} 
No cenário midiatizado, a aparência física assume um protagonismo, sendo que "o corpo se torna uma espécie de objeto de design que deve ser constantemente cuidado e renovado" (SIBILIA, 2016, p. 151). No caso de Pabllo, a artista transita entre gêneros com muita propriedade, com uma estética bem elaborada.

Constatamos também que os vídeos, no Instagram, apesar de obterem grandes quantidades de visualização, não são boas estratégias para conquistar curtidas e comentários dos internautas. Apenas um vídeo de Pabllo, entre as 181 postagens, foi selecionado em nosso levantamento de dados, como sendo o quarto mais comentado.

Há também de se fazer um adendo: a análise dos comentários e das curtidas já partem de dentro de um universo de pessoas que lidam com Pabllo Vittar nas redes sociais. Assim, os contrassensos gerados e as disputas ideológicas que sua presença suscita socialmente não estariam tão presentes em suas redes. Nosso maior intuito, no entanto, era de compreender quais características são as mais celebradas da cantora de acordo com seus engajamentos e assim iniciar a compreensão de como um tabu social, como a performance drag, tem conseguido caminhar em direção ao mainstream.

Consideramos que a comunicação instagramizada de Pabllo Vittar possui, em alguma porção, interesses de mercado, visíveis, especialmente, nas publicações enquadradas na categoria "outros", onde, por exemplo, a cantora promovia singles, shows, etc. Entretanto, diferentemente de outras webcelebridades que direcionam suas subjetividades e mercantilizam afetos na busca de uma gestão de si como marcas, a artista parece não espetacularizar sua intimidade apenas como vitrine midiática, mas como uma plataforma real, subjetiva, que se alinha, logicamente, às suas dinâmicas mercadológicas. Mesmo que a maior parte de suas postagens envolvam estar produzida e montada como drag queen, as fotografias, geralmente simples e cotidianas, não intentam em transparecer algo que não se é, ou seja, melhorar e higienizar sua imagem pela escolha apenas de fotos de alto qualidade de produção.

Vera França (2014) pondera que as personalidades da mídia constroem sua reputação em determinados contextos e condições, sendo que elas estão "estreitamente 
relacionadas ao quadro de valores de uma sociedade" (FRANÇA, 2014, p. 32). Assim, "o perfil das celebridades do século XXI são das marcas de nosso tempo" (FRANÇA, 2014, p. 33). Nessa perspectiva poderíamos considerar Pabllo Vittar uma das marcas das conquistas das lutas minoritárias do nosso século que, mesmo encontrando severas resistências sociais, vem conseguindo adentrar, especialmente através da mídia, as pautas sociais.

\section{Referências}

AMANAJÁS, Igor. Drag queen: um percurso histórico pela arte dos atores transformistas. Revista Belas Artes, ano 6, $\mathrm{n}^{\circ}$ 16, set-dez 2014. Disponível em $<\underline{\text { http://bit.ly/2xSbKyb }}>$. Acesso em 20/04/2017.

BUTLER, Judith. Problemas de gênero: feminismo e subversão da identidade. Rio de Janeiro: Civilização Brasileira, 2017.

CASTELLS, Manuel. Redes de indignação e esperança. Rio de Janeiro: Zahar, 2013.

FRANÇA, Vera. Celebridades: identificação, idealização ou consumo? In: FRANÇA, Vera et al (org.). Celebridades do século XXI: transformações no estatuto da fama. Porto Alegre: Sulina, 2014.

JENKINS, Henry. Cultura da convergência. São Paulo: Aleph, 2009.

KLEAIM, Luiz Cláudio. Prefácio. In: FERREIRA, Sérgio; MONZELI, Gustavo; RODRIGUES, Alexandro (org.). A Política no Corpo: Gêneros e Sexualidades em Disputa. Vitória: Edufes, 2016.

LEMOS, André. Cibercultura: tecnologia e vida social na cultura contemporânea. Porto Alegre: Sulina, 2013.

OIKAWA, Erika. Dinâmicas relacionais contemporâneas: visibilidade, performances e interações nas redes sociais da internet. In: In: PRIMO, Alex (org.). Interações em Rede. Porto Alegre: Sulina, 2013.

RECUERO, Raquel. Redes sociais na internet. Porto Alegre: Sulina, 2014.

SCOLARI, Carlos Alberto. Narrativas Transmídias: Consumidores implícitos, mundos narrativos e branding na produção da mídia contemporânea. In: Revista Parágrafo, janeiro/junho 2015, v. 1, n. 3, p. 7-19, 2015. Disponível em < http://bit.ly/2hoyoUK >. Acesso em 30/04/2017.

SHIRKY, Clay. Lá vem todo mundo. Rio de Janeiro: Zahar, 2012.

. A cultura da participação. Rio de Janeiro: Zahar, 2011.

SIBILIA, Paula. O show do Eu: A intimidade como espetáculo. Rio de Janeiro: Contraponto, 2016.

SANTOS, Joseylson Fagner. Meu nome é "Híbrida": Corpo, gênero e sexualidade na experiência drag queen. Revista Latinoamericana de Estudios sobre Cuerpos, Emociones y Sociedad. ano 4, no 9 , ago-nov de 2012. 